\title{
Anthony Giddens
}

RESUMO: Nesta entrevista, Anthony Giddens discorre sobre temas contemporâneos que instigam as ciências sociais no estudo de fenômenos sócio-econômico-políticos mundiais e suas relações com a América Latina e o Brasil.
Entrevista concedida a Maria Lúcia Garcia Pallares-Burke, publicada parcialmente no jornal Folha de S. Paulo, caderno Mais, 02/03/97, p. 5-10.

\section{UNITERIMOS:} sociologia, Brasil, LSE, Fernando Henrique Cardoso.

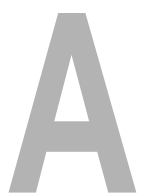

famosa London School of Economics and Political Science, a escola da University of London mais conhecida pela sigla LSE, acaba, ao que tudo indica, de iniciar uma nova fase na sua existência de mais de um século. Seu novo diretor, o renomado sociólogo Anthony Giddens, pretende fazer dois acréscimos substanciais à sua inquestionável excelência acadêmica: transformá-la num importante centro cultural de Londres e envolvê-la na elaboração de uma nova agenda política, tarefa que, segundo ele, se tornou inevitável após a derrocada das antigas divisões entre esquerda e direita.

Fundada em 1895 pelo casal de sociólogos e historiadores socialistas Beatrice e Sidney Webb - e com o apoio de socialistas da Fabian Society, como Bernard Shaw - a histó- ria da LSE mostra que, diferentemente do que suas origens poderiam fazer supor, ela procurou pautar seu trabalho pelo espírito de imparcialidade e abertura. Exemplo disso é que tanto encontramos em seus quadros os idealizadores do estado de bem-estar social, como Beveridge e Marshall, como também defensores da economia de mercado, como Hayek, um dos vários ganhadores de Prêmio Nobel que a escola orgulhosamente coleciona. A variedade de perspectivas que seus dezoito departamentos têm abrigado ao longo do tempo - e que possibilitou o trabalho de figuras influentes e diversas como, por exemplo, H. Laski, K. Popper, K. Mannheim, B. Malinowski, R. H. Tawney e E. Power - se reflete também na variada clientela que a LSE atrai. A diversidade étnica dos seus alunos de graduação e pós-graduação (quase 400 brasi- 
leiros nos últimos 10 anos) faz dela um centro cosmopolita extremamente fértil para o diálogo cultural e intelectual. Quanto ao sucesso dos que passaram por seus bancos, basta lembrar que dentre seus ex-alunos - oriundos de uma centena de países - se encontram, pelo mundo afora, 23 primeiros-ministros, presidentes ou chefes de Estado, 41 presidentes de bancos, 120 ministros, embaixadores ou consultores de governo e 26 diretores de instituições de ensino superior.

Segundo os admiradores de Giddens, suas credenciais acadêmicas, administrativas e empresariais o qualificam amplamente para fazer com que a LSE dê uma contribuição decisiva aos rumos de um mundo envolvido em um processo de globalização sem precedentes. Autor de 30 livros - que tratam desde a sociologia do suicídio e das emoções até a teoria da estruturação social e as consequiências da modernidade - traduzidos em 22 línguas, uma medida de sua reputação intelectual é o que se chama de "indústria Giddens", ou seja, os vários livros dedicados por outros autores à discussão da suas idéias. "Se houvesse prêmio Nobel de Sociologia, Giddens estaria no topo da lista", disse recentemente um de seus entusiastas colegas. Enquanto administrador, um de seus grandes feitos foi estabelecer a Faculty of Social and Political Science na Universidade de Cambridge, lugar hostil a inovações, e onde as ciências sociais ocupavam até o fim da década de 60 uma posição bastante marginal. Quanto a seus dotes empresariais, a reputação e o sucesso da Polity Press, editora por ele fundada há dez anos, são por si só testemunhos de suas múltiplas habilidades.

Nem tudo será, no entanto, um mar de rosas nessa nova carreira de Giddens. Manter a excelência da LSE e ampliar a sua esfera de atuação envolve a questão extremamente polêmica e delicada do ensino público pago. Em princípio já aprovada a cobrança de anuidades por um comitê central, dependerá de Giddens, no entanto, a implementação ou não de uma medida que tem atraído, em antecipação, reações divergentes e apaixonadas. Uma outra tarefa que o aguarda, essa bem mais agradável, é a entrega do grau honorário de DSc (Doctor of Science) a Fernando Henrique Cardoso, homenagem de uma escola que se orgulha de todos os cientistas sociais que se destacam no cenário público mundial.

Dez dias após sua posse, ocorrida a 6 de janeiro de 97, Giddens nos recebeu em sua sala na LSE. Diplomata e cauteloso, de fala mansa e quase monocórdica, e com modos de alguém ao mesmo tempo firme, confiante e despretensioso, ele falou sobre suas novas ambições, sobre os impasses das universidades e da modernidade, sobre as fraquezas do neoliberalismo, sobre as realizações de Fernando Henrique Cardoso etc.

Um de seus mais eminentes predecessores, $R$. Dahrendorf, ao assumir a direção desta mesma instituição disse que "uma universidade não quer e não precisa ser dirigida... basicamente ela se dirige por si só através de seus misteriosos 'caminhos habituais'”. O que acha dessa visão?

Concordo com ele que uma universidade não é uma empresa e que não pode ser dirigida como se fosse um negócio. Por outro lado, acho que hoje em dia a universidade também tem de ser guiada, a liderança sendo crucial para o seu destino. Acredito que quando Dahrendorf fez aquela afirmação as universidades eram completamente financiadas pelo Estado e tinham um número de estudantes bastante estável. Agora, ao contrário, elas enfrentam os mesmos problemas de muitas outras instituições modernas: de um lado, o Estado não mais vai sustentá-las totalmente e, de outro, elas não podem ser deixadas inteiramente nas mãos da iniciativa privada porque não se encaixam na filosofia do mercado. Instituições como hospitais e universidades, por exemplo, têm de encontrar um meio de se 
reestruturar num tipo de associação entre o Estado e os incentivos de mercado. Numa era em que fica mais e mais evidente que os serviços públicos não vão ser mais financiados como antes, o desafio dessas instituições - e isso, acredito, em muitas partes do mundo - é descobrir que espécie de parceria deve ser criada para enfrentar de modo eficiente, e sem nostalgia, uma nova era.

\section{LSE?}

$O$ que o atraiu para essa posição na

Uma série de coisas. Em primeiro lugar, estava em busca de uma nova ambição. Tendo estabelecido em Cambridge a Faculty of Social and Political Science e a Polity Press achei que já havia feito lá tudo o que podia fazer. Dirigir a LSE, a mais famosa instituição de ciências sociais do mundo, me pareceu uma oportunidade incrível de influir no diálogo intelectual e também no programa político do governo. Quando, após 1945, o estado de bem-estar social estava sendo construído, a LSE desempenhou um papel central. O Primeiro Ministro da época, Clement Attlee, era um professor da LSE; Harold Laski, também professor, era chairman do Partido Trabalhista. Outras importantes figuras da LSE, como T. H. Marshall e Beveridge, foram os idealizadores do estado de bem-estar social. A LSE foi, pois, uma instituição que exerceu uma influência pública maciça, não só no plano nacional como mundial, já que o estado de bemestar social se tornou um fenômeno global. Não vejo porque agora, sob minha direção, não possa se iniciar uma espécie de renascimento da influência que teve no passado. Pois eis-nos aqui, no final do século 20, sabendo que as divisões entre esquerda e direita não significam a mesma coisa que no passado, e sabendo também que, devido à expansão do mercado e da tecnologia, o mundo está mudando numa rapidez sem precedente. Diante disso, precisamos tanto interpretar os novos rumos que o mundo está tomando como pensar numa resposta política razoável a essas mudanças. Nesse quadro, acredito que a LSE possa novamente fornecer recursos intelectuais para atender a essas novas necessidades e também influenciar a reação do governo diante desse novo estado de coisas. Sim, pois, no meu entender, as velhas instituições governamentais não podem se sustentar do mesmo modo que antes. Este é realmente um mundo muito diferente, que não só assiste ao colapso do socialismo e do keynesianismo, mas que deve enfrentar um futuro que se torna mais e mais imprevisível. Seguramente precisamos de algo bem mais concreto e prático do que a resposta pós-modernista, que simplesmente cruza os braços diante do colapso do comunismo e das frustrações da modernidade. Dizer que o mundo escapou do nosso controle, que nada podemos fazer, que entrou numa espécie de Idade Média e que só nos resta sorrir e ser irônicos, como quer o pós-modernismo, é, no mínimo, insensato. Há coisas que não só se pode como se deve fazer tanto no plano intelectual quanto prático.

Uma das mais importantes questões politicas que o senhor terá que enfrentar é a que diz respeito à introdução do ensino pago na LSE, sabendo que qualquer que seja a decisão final dessa instituição de ponta ela servirá de modelo para outras instituições de ensino superior britânicas. Como no Brasil, onde essa questão polêmica tem sido também discutida, alguns argumentam que a cobrança é antidemocrática, e outros, ao contrário, que não cobrar é que é antidemocrático. O que pensa dessa polêmica?

Só posso responder a isso de um modo muito geral porque ainda estou estudando a situação financeira da LSE. Mas, em princípio, há dois aspectos nessa questão: é, em geral, uma minoria da população que se beneficia da educação universitária e não é razoável imaginar que todo o restante da sociedade deva simplesmente financiar essa minoria. Diante disso, as universidades por todo o mundo estão tendo que fazer 
uma reestruturação financeira que, acredito, terá necessariamente que envolver muita contribuição monetária das pessoas que usufruem desse ensino. De outro lado, qualquer que seja o sistema de financiamento escolhido, é crucial, no meu entender, que se defenda o acesso dos alunos mais pobres ao ensino superior. Toda a questão da estratificação na sociedade moderna é realmente muito difícil e é uma tolice imaginar que seja fácil de ser resolvida. As universidades, assim como as instituições de serviço médico, refletem a sociedade mais ampla e não podem resolver sozinhas os problemas da estratificação social. Em sociedades como a nossa ou outras, como a brasileira, que são muito polarizadas, as universidades devem desempenhar um papel no processo de democratização, mas só podem fazêlo em conjunto com outros programas de democratização e igualização. A maioria dos esquemas em pauta propõe usar o pagamento dos alunos de maior poder aquisitivo, feitos através de empréstimos ou não, para manter os alunos menos afluentes. Imagino que algo como isso terá de ser feito.

Ouve-se falar muito, ultimamente, de sua grande afinidade com Tony Blair, o provável futuro primeiro-ministro. Como o senhor vê o papel da LSE num governo trabalhista, após décadas de um governo conservador que, de acordo com seus muitos críticos, solapou a educação britânica?

Em primeiro lugar, devo dizer que falei com Blair em várias ocasiões, mas não sou e não pretendo ser seu consultor direto. Acho que isso nem seria apropriado para mim enquanto diretor da LSE. O que eu sou é um simpatizante do projeto de Blair, que entendo que seja pautado pelo reconhecimento de alguns pontos: de que o mundo está mudando em seus traços fundamentais, de que a globalização determina mudanças de todos os níveis na vida das pessoas, e de que, diante do fato de que a realidade de hoje é muito diferente da de 20 ou 30 anos atrás, não se pode mais depender das velhas soluções de esquerda. Acredito, pois, que o que Blair está tentando é fazer com que o Partido Trabalhista rompa com a velha esquerda, mantendo-se, ao mesmo tempo, fiel a seus ideais de combate à desigualdade e de luta pela justiça social. Só que, hoje em dia, o desafio é tentar conciliar o ideal de justiça social com um mercado global competitivo. Não penso que Blair tenha produzido um programa final de governo a partir dessas noções, mas, afinal de contas... quem já conseguiu? Contrariamente ao que muitos pensam, considero que Blair é o oposto do conservador. Ele está pensando ousadamente e procurando se afastar das tradições de seu partido. E, se vocês, no Brasil, conseguiram ter um sociólogo como presidente, não acho muito fantasioso querer que a sociologia influencie o projeto de Blair.

Quão importante é a América Latina em geral e o Brasil, em particular, para o senhor e a escola que dirige?

Não conheço ainda a escola suficientemente para dar uma resposta muito detalhada sobre isso. O que sei é que há muitas pessoas na LSE bastante interessadas e conhecedoras da América Central e do Sul. Quanto a mim, no entanto, posso dizer que o Brasil me interessa particularmente não só por ser uma das maiores economias globais, mas porque ali se vêem bons exemplos das tendências e problemas mundiais que desafiam o mundo moderno. Em alguns aspectos, penso que o Brasil está na vanguarda de outros países, em outros bem atrás. Temos, de uma lado, uma sociedade bem sucedida economicamente mas, de outro, este sucesso está confinado a uma minoria da população. É também uma sociedade com uma história bastante interessante de relações étnicas, e apesar de se poder dizer que quanto mais alto na escala social se está mais branco se é, quando se compara o Brasil com os EUA a diferença é gritante. O grau de segregação que lá se encontra não existe entre vocês. No Rio fiquei realmente impressiona- 
do com uma miscigenação tão visível e tão rara. Pessoas jogando bola na praia e todas se misturando é o que não se vê na maioria dos demais países. A vivacidade essencial brasileira - que deve ser o resultado da cultura e não da economia - faz também do país um lugar especialmente interessante e atraente. Eu penso que o que acontece no Brasil provavelmente tem a chave para o que acontece, em certo sentido, em toda a América Latina. É, pois, um país-chave no palco mundial.

No Brasil, os economistas adquiriram nas últimas décadas um status bastante alto que, paradoxalmente, não diminuiu com o fim do chamado Milagre Brasileiro e os crescentes problemas econômicos que o país passou a enfrentar. Para alguns, o poder e a autoridade que os economistas usufruem são bastante injustificados. Concorda com essa crítica? E diria que os sociólogos ou cientistas sociais são, em geral, mais qualificados para exercer poder e autoridade?

É, na verdade, fácil entender que em uma época em que o neoliberalismo é a teoria dominante, os economistas ocupem uma posição central. Querendo ou não, com a morte dos velhos sonhos marxistas estamos vivendo numa "civilização dos negócios", e neste tipo de civilização a teoria da concorrência e a economia de mercado (em que se resume, essencialmente, o neoliberalismo) desempenha um papel central. Por outro lado, estamos, acredito, aprendendo a reconhecer as limitações e as dificuldades do neoliberalismo, que são de vários tipos. Em primeiro lugar, é uma espécie de filosofia contraditória que mistura autoritarismo moral com filosofias libertárias de mercado. As mesmas pessoas que se curvam às leis do mercado querem Estado e família fortes. Ora, essas duas exigências são contraditórias, incompatíveis. Em segundo lugar, é inegável que o mercado não pode tomar decisões de longo alcance e que questões centrais da humanidade, como as ecológicas, por exemplo, não podem ser resolvidas por ele. Em terceiro lugar, o mercado parece produzir conseqüências polarizadoras, o problema da estratificação social sendo um dos mais cruciais. O que é bem óbvio no Brasil está se tornando também mais e mais óbvio na Europa, onde é visível uma crescente desigualdade econômica após um período em que a igualdade estava crescendo e se impondo. Tudo isso exige algum tipo de solução que talvez seja achada por alguns teóricos da economia, mas que serão, com toda probabilidade, pensadores bem diferentes dos neoliberais: economistas que certamente pensarão mais historicamente, mais em conjunto com outros cientistas sociais, e que estarão interessados em ver as questões não só sob um ângulo predominantemente técnico.

Como se sabe, Fernando Henrique Cardoso, um eminente sociólogo de esquerda, como o senhor, tem sido acusado de conduzir uma política neoliberal desde que se tornou chefe de estado. Como vê esta mudança?

Acho que qualquer um na sua posição seria alvo desta acusação. A mesma crítica é feita aqui contra Blair, apesar de ele não ter começado como um sociólogo, mas, sim, como membro de um partido que tem uma tradição de esquerda; e, segundo os críticos, Blair está se deixando seduzir por uma filosofia de direita. $\mathrm{O}$ que imagino que Cardoso esteja tentando fazer - e o que é muito difícil quando se está no poder - é realmente encontrar um caminho para além do velho dilema direita-esquerda. Na verdade, superar esse dilema é o que todos nós ou fomos liberados para fazer ou estamos condenados a fazer. Quero dizer que há muitas questões - como as ecológicas e as relativas à globalização - que claramente escapam ao simples dilema entre esquerda e direita. Dito isto, é, no entanto, verdade que como o neoliberalismo é tanto a ideologia da globalização quanto a teoria da globalização, parece inevitável que se tenha de se adaptar um pouco a 
ele, não importa o que se tente fazer no país. Apesar de tudo, estamos todos tentando imaginar qual poderia ser uma outra teoria política. Quando se está no poder é bem mais difícil pensar teoricamente e haverá sempre os que dirão que não estamos agindo de acordo com nossos ideais. Lembremos que Max Weber disse que se tem, na verdade, duas escolhas: ou se é um intelectual, relativamente puro, ou se é um líder político que necessariamente está envolvido com o poder, a política e todos os compromissos que isso implica. Considero que tentar unir essas duas coisas é algo que denota bastante bravura. É bem mais fácil permanecer na biblioteca e condenar os que ousam fazer isso. Não quero, entretanto, dizer que os intelectuais se tornam necessariamente bons líderes políticos, do mesmo modo que acho que bons líderes não são necessariamente bons intelectuais. Nisso Weber estava certo, pois parece que normalmente as vidas contemplativa e ativa exigem personalidades diferentes, com algumas poucas exceções. Estou muito longe de ser um especialista em Brasil, mas por tudo que sei parece que Cardoso fez fundamentalmente um bom trabalho diminuindo a inflação. Haveria algo mais significativo do que isso a ser feito nesse curto espaço de tempo? Acredito que não. Quanto a saber se essa realização vai ser duradoura, só se pode especular. Um livro recente chamado The death of inflation sugere que a queda da inflação é parte de uma tendência global e que, portanto, se um hábil líder político conseguir se unir a essa tendência, a inflação pode cair e se manter assim. Mas, fora especulações como essas, as coisas não são previsíveis e, no meu entender, a queda da inflação é umas das grandes realizações de Cardoso. Outra questão é que para ninguém ainda está muito claro qual deveria ser a alternativa ao neoliberalismo. O que se sabe claramente é que não deve ser a restauração do keynesianismo - que era a teoria de esquerda típica, defensora da colaboração dos sindicatos e do Estado e da redistribuição da riqueza através do estado de bem-estar social. Há muitas pessoas que gostariam de assistir a um renascimento disto, o que não é possível. Suponho que Cardoso seja contra o que eu chamo de nostalgia de direita ou de esquerda. Entendo por nostalgia de esquerda a nostalgia dos sonhos do estado de bem-estar social, enquanto que nostalgia de direita é a nostalgia da chamada família tradicional e dos símbolos tradicionais da nação. Para os nostálgicos de uma ou outra ordem, é muito fácil criticar as pessoas no poder. É possível que Cardoso tenha cometido grandes erros, mas como um observador de fora eu diria que ele, dentro dos limites do possível, conseguiu muito.

Para os países que estão na periferia ou na semiperiferia da vida intelectual do ocidente parece que os centros não prestam muita atenção ao que é produzido fora deles. Pensando no Brasil, podemos, por exemplo, nomear sociólogos, como Florestan Fernandes, que fizeram contribuições bastante inovadoras ao pensamento sociológico desde os anos 50, mas que são desconhecidos dos intelectuais ingleses, com exceção dos brasilianistas. Concorda que há, de fato, um tal descaso? Se sim, o senhor tentaria sanar isso procurando desenvolver um tráfico de idéias em duas direções e criar condições para uma um verdadeiro diálogo intelectual?

Essa é uma situação que existe, de fato, em muitas partes do mundo, mas que, no meu entender, está melhorando bastante nos últimos tempos. O que me impressiona quando viajo é verificar que o debate intelectual está se tornando muito mais globalizado. Você encontra pessoas discutindo os mesmos problemas em todo o mundo, o que significa que intelectuais de várias origens podem se comunicar porque há muito menos dificuldades, menos tradições intelectuais diferentes do que no passado. É inegável, no entanto, que o imperialismo da língua inglesa é uma realidade difícil de contra-atacar e que gera problemas. Há, por exemplo, traba- 
lhos inferiores escritos em inglês que dão fama aos seus autores e trabalhos superiores escritos, por exemplo, em português que não são traduzidos e relegam seus autores à obscuridade. Isso é o que tem acontecido e não tenho uma solução muito clara para isso. Eu espero que a LSE seja um centro de comunicação dialógica porque, no meu entender, o futuro do mundo depende do diálogo para combater a violência. Quer sejam duas nações, duas áreas culturais, ou dois indivíduos, o mundo só poderá sobreviver se as pessoas puderam conversar umas com as outras, entender umas as outras. Na verdade, acredito que esse diálogo intelectual já está sendo implementado pois a democracia é uma das idéias triunfantes da atualidade. Não há, hoje em dia, muitos estados no mundo que ousariam não se chamar de democráticos, apesar de poderem, na realidade, não o ser. De qualquer modo, democracia pressupõe diálogo, soluções comunicativas para problemas que no passado eram resolvidos pela violência. Estamos, pois, assistindo ao fomento de instituições democráticas não somente dentro dos estados nacionais, mas em termos transnacionais. Sem negar todos os riscos que o futuro implica, as forças já estão, em certo sentido, aí a produzir diálogo, a produzir comunicação.

O senhor acha que os teóricos sociais devem preferencialmente buscar leis gerais que governam qualquer sociedade ou, ao contrário, que eles devem, como os teóricos da dependência, partir de diversidades - como, por exemplo, a tensão entre centros e periferias e teorizar a partir dessas perspectivas?

Penso que não se pode começar com nenhuma das duas; tem-se que partir, em certo sentido, de ambos os pólos. Sou muito contrário à idéia pós-moderna de que tudo é relativo ao contexto, que só há diversidade, pois acredito na existência de forças muito gerais movendo o mundo; por exemplo, os mercados monetários mundiais têm uma influência fantástica no di- nheiro que cada um carrega no bolso. Ora, isso não é diversidade, mas, sim, uma espécie de estandardização. Pode não haver leis universais sobre isso, mas certamente há a necessidade de se generalizar, já que é uma situação que gera consequiências para todas as regiões do globo, inclusive as menos desenvolvidas. Tem-se, então, que relacionar o geral e o particular e negar a idéia de que não se pode mais generalizar sobre nada. Afirmar que só há diversidade e que não existe qualquer afirmação válida que possa se aplicar a todas as diversidades é, essencialmente, uma falsa idéia pós-moderna.

O senhor escreveu um livro de grande sensibilidade sobre a intimidade e, ao mesmo tempo, tem a reputação de ser alguém que nunca se mostra em seu trabalho e de ser uma pessoa fria, que esbanja em eficiência, mas que carece de emoção; uma pessoa "tão seca como um biscoito", conforme a descrição do The Times. Como explica esse aparente paradoxo?

Por aí se vê como as notícias correm! O jornalista que me descreveu como sendo seco como um biscoito estava se baseando nas informações contidas no Who's Who (que eu próprio não forneci, pois não me importo com isso), onde não consta nenhum interesse ou hobby meu. Quanto a ser uma pessoa fria, não me vejo como tal, preferindo, no entanto, deixar meu lado pessoal fora do domínio público. Mas, talvez ajude saber que eu não teria escrito esse livro sobre a sociologia das emoções não fossem os 5 anos de psicoterapia que me ensinaram a me perceber melhor, a ver melhor os outros e me despertaram intelectualmente para a importância das emoções, assunto banido das ciências sociais e, talvez de um modo geral, da cultura intelectual do ocidente. A vida sexual e emocional tem muito mais impacto na cultura intelectual do que é usualmente reconhecido. Há dados sobre a intimidade de Marx e Max Weber e sobre suas vidas emocionais torturadas que são bastante reveladores da importância crucial das emoções 
na trajetória intelectual das pessoas. Weber, por exemplo, sabe-se que foi a pessoa mais fria e sexualmente reprimida que se possa imaginar. Pois bem, uma coleção de suas cartas - que a Polity Press pretende publicar - revela quão determinante para a sua obra foi, por exemplo, o seu envolvimento com movimentos sexuais libertários, e quão criativo foi o período em que ele - que parece não ter jamais consumado seu casamento - teve várias amantes!

Recebidopara publicação em setembro/1997

UNITERMS:

sociology,

Brazil,

LSE,

Fernando Henrique

Cardoso.
GIDDENS, Anthony. Interview to Maria Lúcia Garcia Pallares-Burke. Tempo Social; Rev. Sociol. USP, S. Paulo, 10(1): 121-128, may 1998

ABSTRACT: In this interview, Anthony Giddens speaks about contemporary problems of the social sciences and their relationship with Latin America and Brazil. 